\title{
Progression of thrombogenesis in large coronary aneurysms during anticoagulant therapy in a Buerger's disease patient
}

\author{
Daisuke Tezuka, Go Haraguchi, Hiroshi Inagaki, Mitsuaki Isobe
}

Department of Cardiovascular Medicine, Tokyo Medical and Dental University, Tokyo, Japan

Correspondence to Mitsuaki Isobe, isobemi.cvm@tmd.ac.jp

\section{DESCRIPTION}

Buerger's disease results in thrombotic obstructions in small-sized and medium-sized arteries and veins in the arms and legs, and more rarely in the coronary arteries. ${ }^{1}$ A patient, a habitual smoker, suffered from severe leg pain, and angiography of arteries in the legs showed typical findings of Buerger's disease, that is, diffuse stenosis with corkscrew collaterals (figure 1A). Five years later, amputation of his legs was needed due to progressing Buerger's disease. During the assessment of his cardiac function, asymptomatic myocardial infarction was diagnosed by echocardiogram showing asynergy of the left ventricular wall with a decreased ejection fraction (40\%) and akinesis of the inferior wall with thinning. ECG-gated coronary CT angiography revealed an occlusive aneurysm in the right coronary artery and large aneurysms in the left anterior descending artery (LAD) and left circumflex artery with lesions extending into the distal portions (figures $1 \mathrm{~B}, \mathrm{C}$ and 2). The LAD aneurysm had a thick thrombotic zone inside the wall (figure 2B,C), and 5 months later, large amounts of LAD thrombosis occluded the aneurysm despite anticoagulant therapy with warfarin (figure $2 \mathrm{~F}$ ). The patient had no medical history of Kawasaki disease. The coronary aneurysms were thought to be due to Buerger's disease. Though coronary lesions of Buerger's disease have been described in past case reports, ${ }^{2}$ the large coronary aneurysm formation observed in this case is rare. The present case highlights the difficulty of controlling thrombogenesis in coronary aneurysms of Buerger's disease with anticoagulant therapy, in such a case, the addition of immunosuppressive therapy should also be considered. ${ }^{3}$

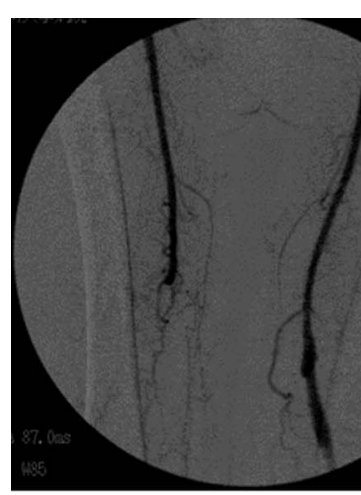

a

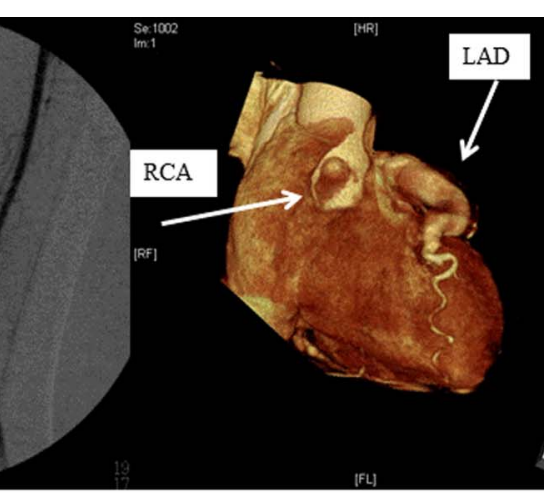

b

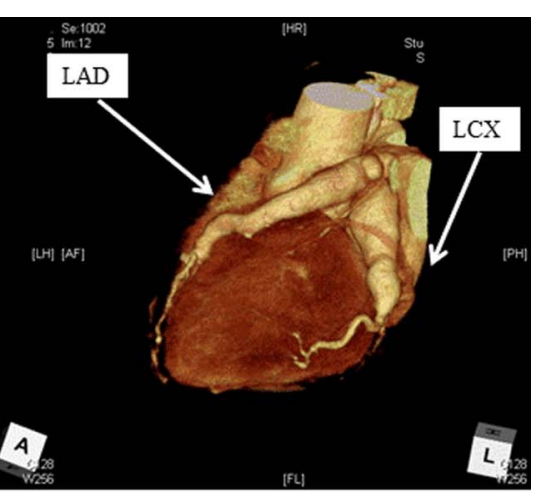

C

Figure 1 (A) The angiography revealed occlusive lesion in the right leg and corkscrew collaterals. Right anterior oblique (RAO) view (B) and cranial left anterior oblique (LAO) view (C) of volume rendering (VR) image reconstructed from coronary CT angiography. The right coronary artery shows an obstructed proximal lesion and the distal lesion cannot be seen. Large aneurysms are present in the left descending artery and the left circumflex artery. 


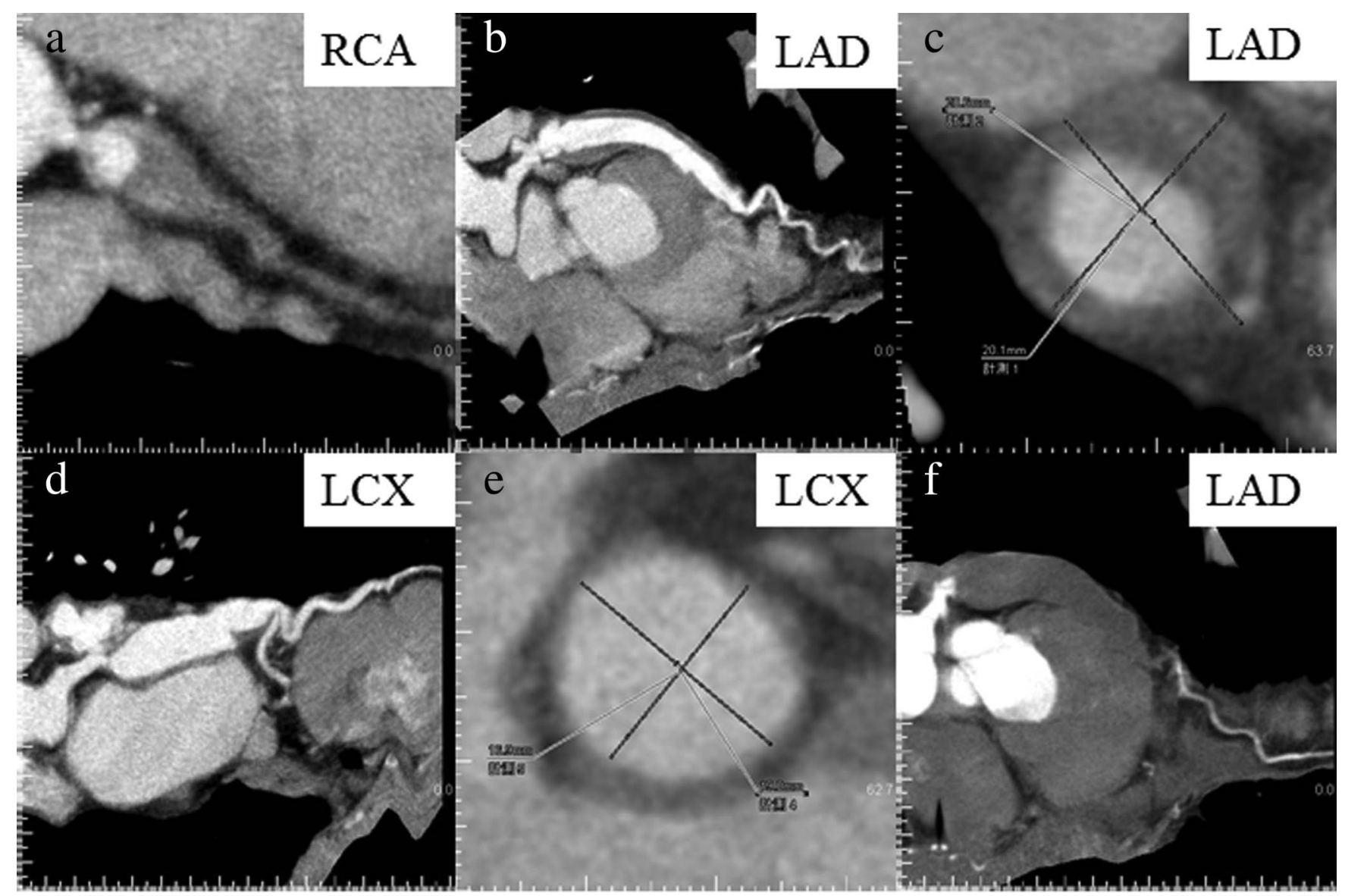

Figure 2 (A-F) Curved planer reconstruction (CPR) views derived from coronary CT angiography. (A) CPR view of the right coronary artery (RCA) aneurysm. The thrombosis obstructs the proximal RCA. (B) CPR view of the left anterior descending artery (LAD) aneurysm. (C) The maximum diameter of the LAD coronal section is $20.6 \times 20.1 \mathrm{~mm}$. (D) CPR view of the left circumflex artery (LCX) aneurysm. (E) The maximum diameter of the LCX coronal section is $19.0 \times 16.9 \mathrm{~mm}$. (F) Five months after starting anticoagulant therapy with warfarin (1-2 mg, PT-INR: 2.3 \pm 0.9$)$, the LAD aneurysm was obstructed by a large amount of thrombosis.

\section{Learning points}

- Buerger's disease results in thrombotic obstructions in small-sized and medium-sized arteries and veins in the arms and legs; however, the disease can form coronary aneurysms like in the present case.

- Coronary CT angiography is useful in the identification of coronary aneurysm, particularly, the imaging modality can visualise not only stenotic lesions but also thrombotic lesions in coronary aneurysm.
Contributors DT wrote the manuscript. GH gave DT useful suggestion in submitting this manuscript. HI was responsible for the clinical management of this case. MI was primarily responsible for constructing the manuscript.

Competing interests None.

Patient consent Obtained.

Provenance and peer review Not commissioned; externally peer reviewed.

\section{REFERENCES}

1 Olin JW. Thromboangiitis obliterans (Buerger's disease). N Engl J Med 2000;343:864-9.

2 Abe M, Kimura T, Furukawa Y, et al. Coronary Buerger's disease with a peripheral arterial aneurysm. Eur Heart J 2007;28:928.

3 Aksu K, Donmez A, Keser G. Inflammation-induced thrombosis: mechanism, disease associations and management. Curr Pharm Des 2012;18:1478-93. 
Copyright 2013 BMJ Publishing Group. All rights reserved. For permission to reuse any of this content visit http://group.bmj.com/group/rights-licensing/permissions.

BMJ Case Report Fellows may re-use this article for personal use and teaching without any further permission.

Become a Fellow of BMJ Case Reports today and you can:

- Submit as many cases as you like

- Enjoy fast sympathetic peer review and rapid publication of accepted articles

- Access all the published articles

- Re-use any of the published material for personal use and teaching without further permission

For information on Institutional Fellowships contact consortiasales@bmjgroup.com

Visit casereports.bmj.com for more articles like this and to become a Fellow 